\title{
Transexualização em Narrativas de Histórias de Vida sobre a Infância
}

\section{Transexuality in Narratives of Life Stories About Childhood}

\section{Transexualidad en las Narraciones de Historias de Vida de la Infancia}

\author{
Alexsander Lima da Silva* \\ Universidade Federal de Alagoas - UFAL, Maceió, Alagoas, Brasil
}

Adélia Augusta Souto de Oliveira**

Universidade Federal de Alagoas - UFAL, Maceió, Alagoas, Brasil

\begin{abstract}
RESUMO
Análise psicossocial do processo de transexualização na infância, por meio das narrativas da infância de três transexuais masculinos e três transexuais femininos, sendo dois representantes de cada geração - mais nova, do meio e mais velha. Identifica-se a produção histórica dos significados de gênero e suas vivências sentidas. Utiliza o referencial teórico e metodológico qualitativo da Psicologia Social e dos Estudos de Gênero. Realiza uma análise de conteúdo descritivo-interpretativa das histórias de vida. As infâncias foram marcadas pelos questionamentos sobre si mesmos e da sua diferença em relação às outras crianças e adaptar-se para serem aceitos. Destacam-se as brincadeiras de criança e estratégias de disfarce na aparência para serem meninos e meninas. Essas são formas de atender aos padrões heteronormativos e evidenciam aspectos fossilizados de significação. Por outro lado, a aceitação por parte dos familiares indica importante elemento de ruptura e de possibilidade de viver a diferença.

Palavras-chave: transexualização, infância, psicologia social.
\end{abstract}

\begin{abstract}
Psychosocial analysis of the transexual process in childhood through the narratives of three male and three female transgender, two representatives of each generation - younger, middle and older. Identifies the historical production of the meanings of gender and their felt experiences. Using the theoretical and methodological quality of Social Psychology and Gender Studies. Recounts the narratives of childhood three male transsexual and three female transexual, two representatives of each generation - younger, middle and older. Conducts a content analysis of the descriptiveinterpretative life stories. Childhoods were marked by questions about themselves and their difference from other children and adapt to be accepted. We highlight the children's games and strategies in disguise looks to be boys and girls. These are ways to meet the standards and heteronormative aspects fossilized evidence of meaning. On the other hand,
\end{abstract}


the acceptance by the family indicates important element of rupture and the possibility of living difference.

Keywords: transexuality, childhood, social psychology.

\section{RESUMEN}

Análisis psicosocial del proceso transexual en la infancia a través de los relatos de tres hombres y tres mujeres transexuales, dos representantes de cada generación - menores, intermedias y mayores. Identifica la producción histórica de los significados de género y sus experiencias sentidas. Uso de la calidad teórica y metodológica de Psicología Social y Estudios de Género. Narra los relatos de la infancia de tres hombres y tres mujeres transexuales, dos representantes de cada generación - más joven, media y mayores. Lleva a cabo un análisis de contenido de las historias de vida descriptivo interpretativa. Infancias estuvieron marcados por las preguntas sobre sí mismos y su diferencia con respecto a otros niños y se adaptan para ser aceptada. Destacamos los juegos de los niños y las estrategias en el encubrimiento parece ser niños y niñas. Estas son maneras de cumplir las normas y aspectos heteronormativos fosilizados evidencia de significado. Por otro lado, la aceptación por parte de la familia indica elemento importante de la ruptura y la posibilidad de la diferencia de estar.

Palabras clave: transexualidad, infância, psicología social.

\section{Introdução}

O processo de transexualização na infância constitui-se enquanto temática de interesse da Psicologia Social. Na sua abordagem, optouse pela investigação qualitativa, com a análise descritivointerpretativa de conteúdo, a partir da perspectiva de sujeitos representativos e teoricamente circunscrita, aos sentidos vivenciados e significados compartilhados do fenômeno da transexualidade.

Esta temática está, cada vez mais, sendo discutida, e o conceito de transexualização parece encontrar ressonância em grande parte da literatura PSI estudada (Bento, 2006; Barbosa, 2010; Bruns \& Pinto, 2003; Carvalho, 2011; Ceccarelli, 2008; Graziottin \& Verde, 1997; Teixeira, 2009; Zambrano, 2003). A pessoa transexual é aquela que não se identifica com o gênero imposto desde o seu nascimento, buscando, então, transformar seu corpo e imagem equivalente à sua identidade de gênero, por meio da transexualização. É importante salientar, ainda, que a transexualidade relaciona-se à reivindicação identitária e não à orientação sexual (Silva \& Oliveira, 2013).

O termo "processo de transexualização", adotado neste artigo, consiste no percurso do autorreconhecimento enquanto transexual e na produção da identidade transexual a partir de experiências pessoais. O sufixo ação permite a ideia de movimento e processo, ampliando a noção para além da cirurgia de transformação corporal ou de transgenitalização. Difere-se do processo transexualizador que é solicitado em instituições e programas de saúde que realizam a cirurgia de transgenitalização. Este incide no uso de roupas femininas 
- transexuais femininas - e masculinas - transexuais masculinos, na utilização de hormônios para surgimento ou diminuição dos seios e/ou pelos corporais - dependendo da escolha do solicitante -, na utilização de próteses de silicone e na própria cirurgia de transgenitalização (Arán, 2006; Arán \& Murta, 2009; Silva, 2013).

No Brasil, o processo transexualizador apenas pode ser iniciado em candidatos que tenham idade igual ou superior a dezoito anos. Por se tratar de intervenção cirúrgica com alteração visual, envolve fatores psíquicos, sendo aconselhável o acompanhamento de uma equipe interdisciplinar de profissionais da saúde e ciências sociais. A transgenitalização apenas ocorre mediante a aprovação dessa equipe. Muitos transexuais consideram negativa essa aprovação ser mediante a equipe de saúde, pois consideram que ferem sua autonomia. (Araújo, 2010; Argentieri, 2009; Bento, 2009; Silva, 2013). Em outros países, como Alemanha, a cirurgia de transgenitalização pode ser realizada a partir dos dezesseis anos, se o (a) candidato (a) for emancipado (a) pelos pais (Silva, 2013).

A produção acerca da transexualização infanto-juvenil ainda é pouco significativa, durante o levantamento bibliográfico foram encontradas poucas pesquisas com foco no processo de transexualidade na infância. Na produção científica, temos estudos (Anacleto \& Maia, 2009) acerca da transexualização infantil e da aprovação dos pais para hormonização. Os casos mais famosos são de Tammy Lobel nascido Thomas Lobel - que iniciou o processo de transexualização aos oito anos e da cantora Kim Petras, que deu início à mudança visual e corporal aos 10 anos, realizando a transgenitalização aos 16 anos. Tais exemplos contrariam a ideia de que a transexualidade e seu autorreconhecimento são fenômenos que ocorrem na adolescência e fase adulta.

Esse artigo retrata as narrativas revividas de histórias de vida de transexuais masculinos e femininos, sobre o período da infância (Silva, 2013). Apresenta como objetivo compreender o processo de transexualização na infância, identificando a produção histórica e social de seus significados e a experiência vivida de seus sentidos. Para tanto, utiliza-se do método da História de vida e do aporte teórico interdisciplinar da Psicologia Social e dos Estudos de Gênero.

$O$ presente texto reflete sobre as seguintes inquietações: como as pessoas transexuais relembram sua infância? Quais os marcadores de significados e sentidos que indicam o processo de transexualização na infância? Quais são os elementos de permanência e de ruptura que estão presentes neste processo? Quais são as ideias compartilhadas e resignificadas nesse processo? Esses questionamentos guiam as reflexões apresentadas ao longo do texto.

\section{Aporte teórico}


A análise aqui empreendida busca, em primeiro lugar, definir o conceito de significação, a fim de se compreender os aspectos fossilizados, difíceis de serem modificados no interior da cultura; depois, buscar esses sentidos vivenciados, a fim de evidenciar as possíveis rupturas e possibilidades de resignificação nesse processo (Molon, 2003; Pino, 2005; Vigotski, 1984/2007, 1987/2008. Assim, de acordo com Vigotski (1984/2007), o sujeito ao inserir-se no meio material e a partir da sua relação com o mesmo, irá produzir sentido e significado, construindo novos conhecimentos, produtos da soma entre as suas experiências consolidadas e o novo, resignificando e edificando novos sentidos.

Nessa direção, as reflexões teóricas, epistemológicas e metodológicas encaminham a uma concepção processual de sujeito, ou seja, um processo de produção da subjetividade, a partir de sua interação com o ambiente social, pois o homem interioriza informações da cultura, codifica com o que já possui e confere sentido e significado (Pino, 2005; Zanella, Dassoler, Reis, Titon, \& Urnau, 2007). Tais reflexões orientam para estudos dos processos culturais e históricos do fenômeno transexual, da relação entre $o$ sujeito e a sua autoidentificação transexual e de procedimentos que evidenciem a processualidade do objeto de investigação em questão.

A transexualidade tem se mostrado um fenômeno que desafia as definições de gênero, se constituindo, assim, em um tema bastante complexo, que abrange a tríade corpo, identidade e gênero. Os estudos de gênero e sexualidade mostram-se relevantes com a crítica à visão binarista, de complementariedade e de dominação entre os sexos, assegurando um novo olhar acerca das diferenciações (Bento, 2006; Butler, 2010; Gagnon, 2006; Hennigen, 2006; Laqueur, 2001; Nicholson, 2000; Stadler \& Carmo, 2011).

Transexuais e travestis perpassam as "divisórias" impostas pelas normatizações e institucionalizações do corpo associado aos binarismos. Através dos seus corpos, performances e reivindicação identitária há uma nova configuração em relação a essas polaridades conceituais. O termo "transexualização" questiona a definição "apenas mudança de sexo", permitindo o vislumbre de um processo. Este desafio permite avançar no estudo e compreensão do fenômeno a partir dos sujeitos que vivenciam esse processo.

\section{Método}

O estudo se caracteriza por ser de natureza qualitativa, pois privilegiou a escuta de narrativa de história de vida de sujeitos, especialmente do período da infância (Chizzotti, 2000; Flick, 2009, 
Minayo, 2002; Turato, 2008; Vigotski, 1982/2010; Zanella et al, 2007).

As histórias são vividas no contexto histórico, social e cultural. Nesse sentido, a produção da história de vida permite identificar o significado e os sentidos experienciados pelos participantes em seu processo de transexualização. A unidade de significação vivenciada na infância nas histórias de vida - dos seis representantes transexuais de cada geração - podem evidenciar aspectos inter e intrageracionais do fenômeno em estudo. Assim, as narrativas possibilitaram aos sujeitos um contato com sua memória e um compartilhamento de histórias de vida. (Ciampa, 2005, Flick, 2009; Humerez, 1998, Ozório, 2007).

O recorte intergeracional busca identificar permanências e mudanças no processo de transexualidade na infância de cada geração, bem como as diferenças e semelhanças entre elas. A memória, a dinâmica das relações intersubjetivas e a história se fazem presentes (Delgado, 2010; Oliveira, Rodrigues, \& Levi, 2010). Por outro lado, o recorte intrageracional permite identificar as nuances de gênero de uma mesma geração. Seja na narrativa ou no ouvir, a produção da cultura de uma comunidade é organizada e a identidade grupal e subjetividade de cada membro vão sendo construídas (Brandão, Smith, Sperb \& Parente, 2006; Lisboa, Féres-Carneiro, \& Jablonski, 2007).

Vale destacar, ainda, que a intergeracionalidade é uma relação entre gerações e não somente o legado de uma para outra, podendo ser transmitida por meio das narrativas e da história oral (Brandão, Smith, Sperb, \& Parente, 2006; Lisboa, Féres-Carneiro, \& Jablonski, 2007). Esses processos da identidade coletiva e individual são conaturais aos sujeitos, pois são herdados através da história. Entretanto, só através da experiência e do vivido que se são edificados e constituídos (Delgado, 2010). Percebe-se, então, que a intergeracionalidade envolve três aspectos em seu processo: a memória, a dinâmica das relações intersubjetivas e a história. Seja na narrativa ou no ouvir, a produção da cultura de uma comunidade é organizada.

\subsection{Procedimento}

A investigação passou por quatro fases: a pré-análise, a leitura do material bibliográfico, a coleta de dados e o tratamento das informações, através da inferência e interpretação (Bardin, 2009). A primeira fase consistiu no levantamento bibliográfico para subsidiar a revisão da literatura do projeto da pesquisa. A segunda envolveu a leitura e escolha do aporte teórico e método. A terceira consistiu na coleta dos dados através dos instrumentos e na produção das 
histórias de vida. E por último, a análise das histórias de vida concluídas.

\subsubsection{Procedimentos éticos}

O projeto de pesquisa foi enviado ao Comitê de Ética em Pesquisa e aprovado com o número 009867 - 2011 -32. A procura pelos sujeitos e convite para a pesquisa foi apenas realizada após a sua aprovação. Optou-se por trabalhar com sujeitos acima dos dezoito anos, por dois motivos: questões éticas envolvendo a pesquisa com menores de idade e pela dificuldade em ter autorização dos pais; método privilegia a narrativa através da memória e recorte inter e intrageracional, sendo mais interessante entrevistar sujeitos adultos que pudessem rememorar suas experiências transexuais na infância. Torna-se interessante enfatizar que os critérios para escolha dos sujeitos foram somente autoidentificação transexual e idade. Dados socioeconômicos do entrevistado e da sua família não faziam parte da pergunta geradora de narração, pois o interesse era em seu processo de transexualização na infância e os significados e sentidos atribuídos ao mesmo. Os representantes masculinos da geração mais nova e do meio e as femininas da geração mais nova e do meio pertenciam à classe média. Os representes da geração mais velha pertenciam à classe média alta. Mas esses dados apareceram durante as narrativas e não demonstraram ser importantes para os entrevistados, visto que raramente eram mencionados ou relacionados às suas transexualizações e à família.

\subsubsection{Procedimentos de coleta de dados}

Após o convite e obtenção do aceite por meio da assinatura do Termo de Consentimento Livre e Esclarecido (TCLE), agendavam-se as entrevistas, respeitando a disponibilidade dos participantes. Estas foram gravadas em áudio do tipo MP4, e transcritas para posterior análise. Os instrumentos principais utilizados foram entrevistas narrativas que consistiam em uma pergunta geradora de narrativa. Solicitava-se que o entrevistado narrasse sua história de vida, desde a infância até o momento atual da entrevista, enfatizando questões relacionadas ao seu processo de transexualização. Vale salientar que o número de encontros foi definido até que o participante inicie a repetição de informações ou afirme que não se lembra de outras situações ainda não narradas. Estas foram apresentadas aos participantes que poderiam modificá-las.

Após essa apresentação, as histórias de vida foram submetidas à análise de conteúdo do tipo descritivo-interpretativa, sempre cotejadas com as transcrições das entrevistas narrativas e com as anotações de diário de campo do pesquisador (Bardin, 2009; Minayo, 
2002). Esta análise buscou o estudo das frases, palavras e características mais recorrentes, dentro do texto narrado, porque evidenciam elementos importantes da história do sujeito e de seu grupo social, devendo ser categorizados (Caregnato \& Mutti, 2006; Chizzotti, 2000; Flick, 2009). Dessa fase, surgiram as três categorias: brincadeira de criança, aparência de menino/menina e a relação com a família. A análise focaliza a relação intergeracionalidade na infância masculina, feminina e intrageracional entre representantes das mesmas gerações.

\subsection{Sujeitos}

Participaram desta investigação 06 Transexuais, sendo 03 masculinos e 03 femininas, com idade entre dezoito (18) a sessenta e um (61) anos. O critério de inclusão dos sujeitos é a autoidentificação enquanto transexual, transformação do corpo e utilização de vestimentas conforme esta autoidentificação, independente da realização da cirurgia de transgenitalização.

As representantes geracionais femininas por ordem crescente de idade: mais nova, mediana e mais velha e seus nomes fictícios, respectivamente, escolhidos pelos próprios entrevistados, e utilizados para suas histórias de vida foram: Gisele, 18 anos, modelo fotográfica, residente em uma capital do Nordeste, entrevista narrativa presencial e gravada. Foram dois encontros com a entrevistada; Joana, 30 anos, universitária, residente em uma capital do Nordeste, entrevista narrativa presencial e gravada, através de dois encontros; Bridget, 48 anos, microempresária, residente em um interior do Sudeste, entrevista narrativa presencial, mas não gravada por pedido da entrevistada. Foram anotadas as falas de sua narração e algumas delas foram sugeridas por Bridget por ocasião da leitura posterior de sua história de vida. Foi um encontro presencial, para a entrevista, e mais 03 por e-mail.

Os representantes geracionais masculinos por ordem crescente de idade: mais nova, mediana e mais velha, e seus nomes fictícios, respectivamente, também foram escolhidos pelos próprios, para suas histórias de vida: Arthur, 22 anos, militante, residente em uma capital do Nordeste, Entrevista narrativa presencial e gravada. Foram dois encontros com o entrevistado; Zé, 48 anos, funcionário público, residente no interior do Nordeste. Entrevista narrativa on-line via msn. Foram 04 encontros com o entrevistado; Sansão, 61 anos, funcionário público, residente em uma capital do Nordeste. Entrevista narrativa presencial e gravada. Foram três encontros com 0 entrevistado.

Gisele, Joana, Arthur e Sansão foram encontrados através do contato com militantes de movimentos transexuais e travestis. O primeiro 
contato com Bridget foi por meio de uma comunidade do Orkut e Zé pelo facebook.

\section{Análise dos dados: a infância relembrada em narrativas}

As brincadeiras de criança, aparência de menino/menina e a relação com a família foram temáticas recorrentes nas narrativas de nossos personagens. A transexualização vivenciada durante a infância apresenta algumas semelhanças: as brincadeiras e os jogos com outras crianças; as estratégias de disfarce da transexualização e o relacionamento com a família e com os amigos.

\subsection{Brincadeiras de criança}

As brincadeiras de Gisele (geração mais nova) foram facilitadas por possuir uma aparência feminina, apesar de ter nome masculino e usar roupas masculinas, que podiam adquirir feminilidade com 0 artifício de encurtar as blusas. O uso de cabelos longos e a aparência feminina lhe permitiam uma participação no mundo das brincadeiras de boneca, evitando o mundo dos carrinhos, pois "sempre diziam: ei, parece uma menina, de cabelão e tudo." O pai a levara a um psiquiatra que a diagnosticou com transtorno de identidade de gênero. Após o ocorrido, seus pais permitiram que a mesma pudesse adentrar ao mundo feminino nos jogos infantis e roupas.

Joana e Bridget (geração do meio e mais velha) parecem ter tido mais dificuldade: Joana precisava aparentar ser menino, brincar de bonecas às escondidas e se percebia diferente dos meninos, que preferiam jogar futebol. Criava estratégias de disfarce para transitar entre os dois grupos e participar de brincadeiras femininas. Joana ainda se permitia disfarçar o olhar ao se interessar por outro menino e elogiava as meninas para evitar uma possível identificação como homossexual.

Bridget também brinca com crianças e relembra ter preferências por assistir desenhos femininos e jogar amarelinha, evitando jogar futebol ou bolinha de gude, embora tenha sido forçada pelo pai a participar desses jogos. Alega que "não queria ser chamada de maricas por brincar apenas com meninas." Afirma que não era agredida pelos outros meninos, pois os mesmos a achavam fraca e sentiam "pena de machucá-la". Gostava de assistir filmes com atrizes como Marylin Monroe e Bridget Bardot, imitando suas poses, falas e trejeitos em frente ao espelho.

Assim elas relembram quando eram crianças:

Eu brincava mais na verdade, eu não brincava com meninas. Até hoje eu não gosto muito de andar com meninas, não sei 
porquê, pois a maioria gosta, vê logo que é gay, aquele rapaz no meio de um monte de menina. Eu não, não gostava. Eu gostava de andar com menina e menino, tudo junto. Mas na hora das brincadeiras, era assim homem só gosta de brincar de bola, né? Mas eu não queria, não vejo graça, em ficar olhando e correndo atrás de uma bola. Aí inventava que o pé tava doente, eu ficava olhando os meninos jogando bola. Ai eu ia brincar com as meninas de boneca, tava nem aí, até porque as meninas são mais compreensivas, né? Eu brincava de boneca, de casinha, escondido, quando ia na casa delas. Era assim a minha brincadeira (Joana).

Quando eles falavam de meninas, eu ficava voando, tapeava: "- ah é bonitinha essa menina", mas parava por aí, não tentava me aprofundar no assunto. Aí quando aparecia um cara bonitinho e isso quando eu era criança, que sempre rola isso, né? Eu tinha que primeiro olhar para todo mundo, para poder olhar para aquele cara, para ver se alguém tava olhando, para não descobrirem, pois eu tinha medo que descobrissem (Joana).

Sempre ganhei boneca, brinquedo de menina meu pai ainda trouxe, uma vez, um carrinho eu quebrei e disse que queria boneca e não brinquedo de menino. Sempre brinquei de boneca e ganhava boneca. Eu comecei a pesquisar mesmo, quando comecei a ter um raciocínio, com meus 15 anos que comecei a procurar, porque antes você pensa como criança, não liga para saber sobre isso. A diferença entre eu e uma menina, é porque ela tem uma vagina e eu não tenho (Gisele).

Como fui criada desde pequena como menina, descarto a possibilidade de ser travesti e transexual. Travesti é o homem que se traveste, que quer parecer com mulher eu não, eu já nasci mulher, com corpo de mulher, semelhança de mulher. Não me viam como mulher antes, porque eu era criança e não tinha corpo desenvolvido, então tinha que usar roupa masculina no início, mas depois me viram como menina (Gisele).

A transexualidade não era uma questão para Gisele durante a infância. Joana e Bridget se percebiam diferente e fora dos padrões. No entanto, Gisele tem convicção que era pertencente ao grupo das meninas. O mundo das brincadeiras parece demarcar as diferenças e marcam as lembranças. Estes estereótipos reproduzem e evidenciam permanências no processo de identificação (Bento, 2006; 2009). Estes estereótipos de gênero compõem o processo de significação que são registros culturais compartilhados e revelam as permanências desses significados sociais que se mantiveram de uma geração para a outra. 
A preocupação de Joana e de Bridget em não serem consideradas diferentes e homossexuais parece ser um aspecto importante no processo de identificação. Ser pela negação. O fato de brincar em grupos mistos era uma forma das diferenças não serem apontadas. Esse momento é demarcado pela estranheza em relação às outras crianças. Gisele se diferencia, pois se percebe como menina desde pequena. Descreve uma facilidade no processo de autoidentificação. As recordações das brincadeiras da infância trazem para Joana, a percepção de maior tolerância e compreensão das garotas, constituindo-se uma experiência afetiva importante. A característica da delicadeza, fraqueza e passividade feminina marca a infância de Bridget, evitando retaliação por parte dos outros meninos. Parece que, contingencialmente, não houve violência dos colegas para consigo: por considerarem-na frágil, ocasiona um tratamento de piedade por parte dos outros garotos. Gisele não teve problemas relacionados às brincadeiras infantis com outras crianças, entretanto os pais a proibiam de usar roupas femininas. Essa proibição é entendida e explicada porque a mesma não tinha corpo desenvolvido, sendo inadequado o uso de vestimentas para meninas.

Pode-se perceber a ruptura entre as gerações no que se refere às brincadeiras de criança. Gisele sempre se considerou menina, seus pais a aceitaram como pertencente ao gênero feminino desde pequena e seus colegas idem. A representante da geração mais nova pouco se utilizou de estratégias de disfarce nas brincadeiras para evitar preconceito, diferente das gerações do meio e mais velha. Esta, por ser considerada fraca, não sofria agressões físicas, apenas verbais. Aquela precisava inventar brincadeiras com grupos mistas, para não ser ridicularizada.

Para os meninos Artur, Zé e Sansão as recordações das brincadeiras de criança são percebidas como um momento marcante de não pertencimento ao universo feminino. Quando crianças, Arthur, Zé e Sansão não se consideravam meninos, entretanto, não se sentiam satisfeitos com brincadeiras, roupas e gestos considerados de menina. Assim, eles relembram:

Eu tinha inveja dos gestos e brincadeiras mais simples dos meus irmãos, eles eram livres no ser. Eu era um prisioneiro de meu próprio corpo. Eu não sei onde aprendi até certos hábitos e maneiras masculinas, elas vinham naturalmente de dentro de mim (Zé).

Quando eu era criança, fiz uma historinha, e coloquei o nome do personagem do menino de Arthur. Era um livrinho de cartolina que você abria as páginas e as figuras ficavam em pé. Aí eu fiz a história do Arthur, que crescia, casava, tinha filhos e era médico e vivia feliz (Arthur). 
Em relação aos representantes masculinos, não existiram rupturas entre as gerações no que concerne às brincadeiras de criança. Os três entrevistados percebiam "as regras" dos brinquedos e jogos para meninos e meninas. Não se sentiam à vontade com as brincadeiras consideradas femininas, mas não se aventuravam a participar das masculinas, pois não se consideravam pertencentes a estas últimas.

Os ideais normativos de comportamento e funções nas brincadeiras infantis de meninos e meninas são edificados a partir do que o meio externo demanda. Este pode ser modificado pela história e experiências humanas (Butler, 2010). Dessa forma, as rupturas expressam mudanças e podem favorecer novos modos de existir. Essas rupturas foram percebidas na geração feminina mais nova em relação às outras duas gerações.

No processo intrageracional, surgiram rupturas e permanências entre os representantes das mesmas gerações. Os representantes da geração mais nova, Artur e Gisele, experimentaram situações diferentes nas brincadeiras de criança: ela com maior liberdade e permissividade, ele não.

Nas gerações do meio, as brincadeiras infantis apresentaram algumas rupturas: Joana criava estratégias de disfarce para transitar entre os dois grupos e participar de brincadeiras femininas. Zé tinha medo de brincar com os meninos, então preferia, forçadamente, participar de jogos femininos. Parece ter sido mais fácil para Joana transitar disfarçadamente entre os meninos e as meninas.

$\mathrm{Na}$ análise intrageracional das gerações mais velhas foram apresentadas semelhanças nas brincadeiras de criança: ambos eram forçados a brincarem com meninos (Bridget) e meninas (Sansão).

Essas recordações nos permitem compreender a diversidade de vivências que marcaram esse período de vida. Essas refletem a importância dos aspectos dinâmicos envolvidos no processo de interdependência entre significado e sentido (Vigotski, 1984/2007, $1987 / 2008$ ). Os sentidos são pessoais, vivenciais, afetivos, e dependem dos diferentes contextos sociohistóricos. Alterar os últimos implica, necessariamente, na modificação dos primeiros. Ambientes acolhedores e respeitosos influenciam positivamente nas experiências de diversidade sexual.

\subsection{Aparência de menina e de menino}

O uso de disfarces parece ter facilitado a vida das crianças. Estar e sentir-se inserido no contexto traz desafios e estratégias de ação. Gisele amarrava um nó e encurtava as blusas masculinas e se sentia "mais menina." Deixar os cabelos longos também auxiliava. Joana não mudou a aparência quando criança, apenas veio a mudar o visual na adolescência, mas para contrastar - e não ser alvo de preconceito - alternava no gênero das roupas. "Eu fui vestindo uma blusinha 
feminina, com calça masculina ou uma blusinha masculina com uma calça feminina", afirma. Bridget vivia sua aparência de menina imitando atrizes e cantoras dentro do quarto, com medo de sofrer represálias do pai.

O sentir-se diferente de Joana e Bridget e a autoafirmação de que era menina por parte de Gisele foram a partir das observações dos comportamentos e "funções" de meninos e meninas que eram diferentes uns dos outros. Esse tipo de diferenciação precisa dos corpos em masculino e feminino, macho e fêmea, origina-se da ideia de uma identidade sexual. Esta última se baseia na visão fisiológica de que homens e mulheres possuem corpos diferentes, e por isso, comportamentos e funções diferenciadas e delineadas (Nicholson, 2000). O corpo, nesse caso, torna-se uma referência para a identidade, por isso espera-se que não seja ambíguo e nem acarrete dúvidas. Os corpos masculinos e femininos - a expressão corpórea, a imagem - são significados pela cultura, mas também modificados pela mesma (Louro, 2000).

Joana e Bridget consideravam-se meninos "diferentes", porque compartilhavam o significado do corpo de um garoto. Todavia, ao usarem de estratégias de disfarce no visual ou na imitação de cantoras, estavam alterando esse mesmo corpo a partir do que entendiam sobre a expressão corpórea feminina. Pode-se perceber, então, uma ruptura entre as três gerações: a mais velha sentia-se "mulher" ao imitar celebridades na solidão de seu quarto; a do meio usava roupas mistas para não sofrer retaliações e, concomitantemente, sentir-se mais feminina; a mais nova adaptava roupas masculinas para femininas, sem importar-se com a opinião alheia. Mais uma vez, a liberdade que o meio propiciava à Gisele, permitia que pudesse expressar seu gênero de forma aberta, sem esconder-se ou necessitar de estratégias de disfarce.

O próprio processo constante de autoidentificação vem ao encontro da relação interdependente entre sujeito e contexto sociocultural (Vigotski, 1984/2007, 1987/2008). Nesse sentido, compreende-se que o entorno de experiências de Gisele em relação à sua transexualização permite que desde pequena se perceba como mulher. No caso de Joana e Bridget, esse processo permitiu que apenas se autodenominassem transexuais na adolescência e na fase adulta, respectivamente. $O$ sentido conferido às suas transexualizações era de estranhamento. Seus corpos estão inseridos culturalmente em papéis determinados para meninos que são diferenciados das meninas, sendo o diferente considerado estranho e anormal (Stadler \& Carmo, 2011). O corpo considerado anormal seria aquele que não estivesse em consonância com o que se entende sobre o que é ser homem ou ser mulher e suas características bastante específicas e divergentes uma da outra, funcionando como extremos que se completam. A nomeação do que é um corpo 
masculino e um feminino é feita de acordo com a cultura e nas relações sociais. O corpo que não está inserido nessas inscrições estabelecidas socialmente passa a ser considerado estranho. Essas nomeações são dispositivos históricos que regulam e normatizam esses corpos (Louro, 2000).

As três transexuais apostaram na adaptação do visual, seja de forma aberta e gradativa (Gisele e Joana) ou dentro do quarto (Bridget), como uma forma de não sofrer preconceito, nem serem ridicularizadas pelos outros. Desse modo, na relação com o outro, que seus comportamentos foram - e continuarão - sendo produzidos (Vigotski, 1984/2007; Molon, 2003, Pino, 2005).

A aparência de menino foi importante também para as estratégias de disfarce para adentrar ao universo masculino, seja nas brincadeiras ou na adaptação visual, que foram utilizadas por Arthur e Sansão. O primeiro cortou os cabelos curtos, mesmo com a desaprovação materna, e, o segundo ficava perto de meninos com piolhos, para ter que raspar o cabelo. Para Zé, essas táticas não foram possíveis, devido ao medo e à grande vigilância de seus pais extremamente religiosos. A ruptura entre as gerações encontra-se presente no uso das estratégias do visual por parte das gerações mais nova e mais velha, enquanto que o representante da geração do meio não se utilizou desses disfarces. Entretanto, percebe-se que essa ruptura está mais relacionada ao meio religioso e intolerante que 0 representante da geração mais velha se encontrava do que as características da época em que aconteceram essas situações. Aparência de menino era uma meta a ser conquistada: para Zé, o uso de vestimentas e gestos masculinos era sinônimo de liberdade do ser. Roupas e brincadeiras femininas eram doloridas. Sansão considerava tudo relacionado ao universo feminino "irritante" e cheio de "frescuras", enquanto que Arthur preferia brincar e agir como menino de forma "inconsciente", porque se sentia bem. Estas experiências foram assim narradas:

Eu não sabia que ia parecer um menino, mas eu queria cortar o cabelo daquele jeito, não sei por que, vai ver era algo inconsciente. Eu sabia que era menina, porque fui criado como menina, com nome de menina, então achava que era menina (Arthur).

Eu sinto assim, desde criança eu olhava para o meu interior e encontrava um menino mesmo que quando eu tomava banho e me via diante do espelho lá refletido um corpo de mulher. Eu tinha inveja dos gestos e brincadeiras mais simples dos meus irmãos, eles eram livres no ser. Eu era um prisioneiro de meu próprio corpo. Eu não sei onde aprendi até certos hábitos e maneiras masculinas, elas vinham naturalmente de dentro de mim (Zé). 
... me forçava a usar cachinhos, eu odiava cabelo grande. Até que um dia... você vai até rir... pra você ver como eu me irritava com cabelos grandes... eu vi que meus irmãos tiveram que raspar o cabelo porque pegaram piolho, pois eu fiz questão de brincar pertinho do piolhento da rua pra pegar piolhos e raspar a cabeça... e foi tão bom não ter que usar cabelo grande, laços (Sansão).

Observa-se, então, que houve uma reflexão anterior e partilhada acerca desses trajes e corpos- que foi passada geracionalmente - e uma nova ponderação dos mesmos, através do contato com o meio. O ser humano incorpora as ideias apreendidas do meio externo e as reinterpreta e resignifica, criando outra opinião. É um acesso processual, simbólico e adaptativo (Vigotski, 1984/2007, 1987/2008). O olhar do outro também implica sobre suas figuras, trazendo mudanças para a adequação dos corpos e da aparência visual, além de conflitos entre o que é necessário mostrar ou se deseja evidenciar (Lima, 2011). O contato com o outro os fazem perceber o que deve ser comparado e adaptado em seus corpos e visuais.

As adaptações de Sansão e Arthur no visual e a visão de um corpo masculino que Zé tinha ao olhar no espelho eram formas de adaptar - ambiente a favor de suas identidades. O comportamento e as funções para cada gênero binário sofrem influências históricoculturais (Gagnon, 2006). Segundo esse autor, em cada cultura existem seus roteiros sexuais. Estes podem ser adaptados pelos indivíduos a partir dos seus contextos. A ideia acerca do corpo masculino e feminino, suas diferenciações e funções, é algo estrutural, que apresenta uma origem, mas que pode ser afetada e contextualizada, a depender da situação e momento histórico.

Torna-se interessante refletir sobre o processo de compreensão da criança ao que é ser menina ou ser menino, visto que estes têm contato com essas acepções já delineadas e compartilhadas pela sociedade (Anacleto \& Maia, 2009). A reprodução dos binarismos masculino e feminino, com suas funções já definidas termina por ser reproduzida socialmente e vistas como formas únicas da expressão de gênero (Laqueur, 2001).

A criança produz a ideia do que se é menino, menina e suas diferenças por meio da história e cultura. Em seu cotidiano edificam comportamentos baseados no que é esperado - e tolerado - para cada função social dos gêneros masculino e feminino e as relações que se instituem entre esses binarismos (Anacleto \& Maia, 2009). Essas mesmas autoras apontam para a importância da educação acerca da identidade de gênero na formação da sexualidade infantil. Essas estratégias de sobrevivência e de inserção no contexto social e cultural são permeadas de sofrimento, pois, ao mesmo tempo em que devem seguir normas externas, devem atender aos desejos e 
inquietações como sujeito (Pino, 2005). O controle, as modelações e adaptações do comportamento atendem às normatizações, pois estas negam as pluralidades e diferenças das contingências dos sujeitos (Hennigen, 2006). Deste modo, percebe-se que esses representantes - em todas as três gerações - entendiam que existiam dois binarismos (menino e menina) com suas regras já estabelecidas na aparência. Não se cogitava ser um menino que usava saias ou uma menina que usava calças masculinas, mas tornar-se uma garota usando roupas femininas ou um garoto trajando roupas masculinas. O não binário não se vislumbrava como uma possibilidade.

Decididamente, porque suas genitálias estão assinaladas e significadas em uma cultura que associa pênis - homem - masculino e vagina - mulher - feminina, em uma lógica exclusivamente biológica e naturalista, as estratégias de adaptação utilizadas estão também presas a esta mesma cultura e tem a finalidade de evitar sofrimento e represálias. Seus corpos estão implantados culturalmente no binarimo macho e fêmea, com suas regras e normas, sendo o diferente considerado uma anomalia que deve ser evitada (Stadler \& Carmo, 2011).

$\mathrm{Na}$ análise intrageracional entre os representantes da geração mais nova foram observadas algumas questões. O parecer menino ou menina se constitui importante demarcador de sentido das experiências transexuais dessa geração. Estar e sentir-se inserido no contexto traz desafios e estratégias de ação. Na autoidentificação transexual as experiências são peculiares: Gisele nunca se autoidentificou como transexual, mas sim como mulher, desde criança. Já Arthur, na infância, se considerava diferente e se autointitulava como menina, porque assim seus pais diziam.

Essa ideia pode estar também associada, novamente, às regras normativas de gênero, visto que a concepção de masculino e feminino está definida pela genitália, como enfatizado na análise intergeracional (Bento, 2006; 2009). Desse modo, seriam ideais impostos por normas sociais e repetida, reafirmada, contraditoriamente, pelos sujeitos que poderiam romper com essas mesmas normas.

$\mathrm{Na}$ análise das gerações do meio há algumas permanências em relação à aparência de menino e menina: ela utilizava-se de táticas para poder transitar sem ser percebida e atender ao gênero identificado, usando roupas masculinas e femininas ao mesmo tempo; ele engravidou na adolescência, mesmo não se considerando uma moça, para dar uma neta aos pais.

Observa-se, então, que, Joana ao adotar roupas mistas, atendendo às suas reivindicações identitárias e, ao mesmo tempo, como forma de disfarce para não sofrer preconceito, termina por subverter as normas estabelecidas dos binarismos masculino e feminino. Zé, ao engravidar precocemente para satisfazer seus pais, se utiliza de algo 
considerado exclusivo das mulheres, mesmo não se considerando uma. A aparência - no uso das roupas e na gravidez - mescla esses dois universos binários e traz uma ruptura a essas regras, mesmo que Joana e Zé não percebessem.

Nas gerações mais velhas, na aparência de menino e menina, o representante masculino utilizava-se de estratégias para ficar com aparência masculina, mesmo que temporariamente, enquanto que a representante feminina tinha medo, preferindo não se arriscar.

Nesse sentido, destaca-se, mais uma vez, como o controle e modelações de comportamento atendem as normatizações, negando as diferenças, as pluralidades, contextos e experiências dos sujeitos (Hennigen, 2006). A transexualidade desses sujeitos questiona 0 binarismo - masculino e feminino - e incomoda as "transgressões" a essas normatizações, através de seus comportamentos e reflexões acerca do lugar ao qual estão inseridos seus corpos, mas que, ao mesmo tempo, precisa atender a essas mesmas normas, através das estratégias de disfarce.

\subsection{As infâncias vividas na família}

Família demarca experiência importante no processo de transexualização na infância das três representantes: Joana relata situações de preconceito, violência e desrespeito. As experiências ruins com seus familiares marcam lembranças de discriminação e intolerância aos transexuais, travestis e homossexuais; Bridget, lembranças de dominação e repressão, visto que era forçada pelo pai a brincar com os meninos. Na geração mais nova há ruptura em relação às outras duas gerações. Gisele confere um sentido positivo à família. Pelo fato de fazer parte de um ambiente familiar mais permissivo, Gisele não sofreu represálias por parte dos familiares. Essa ocorrência alerta para a experiência mais aberta que a representante da geração mais nova parece ter vivido com seus familiares, auxiliada pelo poder da explicação da medicina.

Bem, ele pensava que eu era doida, mas o psiquiatra disse que eu não tinha problema mental nenhum, que eu apenas pensava como menina, tinha cabeça feminina. Depois que o psiquiatra falou isso para ele, ele caiu em si e começou a me ver como menina totalmente. Ele me dava bonecas e me chamava pelo nome feminino (Gisele).

Há rupturas - entre as outras duas gerações - no sentido atribuído ao sentir-se pertencente ao outro gênero. Na geração mais velha, a família que reprime o comportamento, por exemplo, de imitar trejeitos e poses de mulheres, se faz acompanhar de castigos expiados por meio de orações a fim de cura e obtenção de perdão 
divino, ou de aconselhamento de um padre e uma familiar religiosa, como pode ser visto na lembrança de uma das entrevistadas. Bridget dá um sentido de algo sobrenatural e negativo: "eu acreditava que tinha o diabo no corpo, algo ruim no corpo." O sentimento de pertencer ao outro gênero é considerado algo demoníaco. Joana, também reprimida pela família, confere um sentido negativo à mesma: "porque você sabe, a família no lugar de ajudar é a primeira que tem preconceito, que acaba com a vida e detona a vida do homossexual e transexual." Entretanto, a representante da geração do meio não se considerava possuída por alguma força negativa ao sentir-se pertencente ao gênero feminino.

Então, eu era um pouco reprimida pela família, não tinha contato, era da igreja pra casa, da casa pra escola. Foi desde a infância até a adolescência assim, escondendo, escondendo muito, com medo de sofrer violência por parte de membros da família (Joana).

Os representantes masculinos apresentaram algumas rupturas entre as gerações. O modo como a família se relaciona com eles tem peculiaridades: Arthur levava broncas de sua mãe quando usava roupas masculinas ou cortava o cabelo muito curto. Zé passou a se empenhar nos estudos, no trabalho e na relação com a família, procurando "ser o melhor em tudo" para merecer o amor dos pais, pois uma freira, diretora do colégio onde estudava, chamou sua mãe e disse que era uma criança estranha. Sansão ficava trancado no quarto lendo gibis de faroeste para não ser forçado por sua mãe a brincar com as meninas. Os fragmentos abaixo evidenciam essas questões:

Desde cedo descobri que eu era diferente e as pessoas que me cercavam também... lembro quando eu tinha 4 anos minha mãe foi chamada no colégio que eu estudava, pela direção... o colégio era de irmãs, e a freira se dirigiu pra minha mãe e falou que eu tinha um problema, que eu era uma criança estranha...eu nunca esqueci o olhar e as palavras daquela freira... Mergulhei na igreja, nas doutrinas, nas cobranças e julgamentos... e cada vez mais forte eu sentia a divisão dentro de mim.... Eu procurava ser bom em tudo que eu fazia... ser o melhor da sala de aula...ser o melhor filho... (Zé).

Meu pai sempre me tratou bem, nunca ficava no meu pé, acho que por isso ele nem notava que eu era masculino demais. Mamãe notava, porque vez ou outra me empurrava namoradinhos, pretendentes, eu fingia que tudo bem pra ela (Sansão). 
Observa-se que o representante da geração mais nova, mesmo com as proibições, enfrentava seus familiares e mudava seu visual. O da geração do meio preferia "compensar" sua aparente masculinidade empenhando-se em tarefas em que se tornasse bem sucedido. Já o representante mais velho preferia isolar-se da família para que esta não percebesse seu comportamento.

As três gerações apresentaram algumas semelhanças: os três representantes masculinos consideram que apresentar um corpo que não é autorreconhecido, apenas para atender os desejos da família, é sinônimo de sofrimento. Arthur e Zé se imaginavam meninos, mas ficavam tristes ao verem que eram meninas, porque seus pais diziam que assim eram. Sansão irritava-se com os cachos nos cabelos longos e os vestidos que era forçado a usar. Todo corpo é constituído por uma ideia e esta é um modo de expressão do sujeito. Alma e corpo devem estar juntos e em consonância, se um sofre, o outro também padece. Um corpo é recusado porque não é expressão da alma desse alguém (Espinosa, 1971).

Pode-se observar, ainda, que esse olhar sobre o corpo torna-se um instrumento político, visto que atende às necessidades e funcionamentos de determinados grupos. Nesse caso, não adiantaria apenas o sujeito afirmar "eu sou menina" ou "eu sou menino", mas sim atender ao pressuposto do gênero como representante do biológico, através da mudança visual ou da associação do que é exclusivo para uso do homem ou da mulher (Laqueur, 2001).

A relação com a família indica aspectos de permanências na geração do meio e mais velha femininas e nas três gerações masculinas. A reação da família em relação aos seus comportamentos foi de preconceito e/ou distanciamento. Isso se deve ao fato de que a família legitima o que é considerada uma verdade universal pautada em uma crença religiosa ou na observação das diferenças dos corpos - e a atribuição de um sentido negativo ao que é diferente (Anacleto \& Maia, 2009).

$\mathrm{Na}$ análise intrageracional dos representantes mais novos, a reação da família parece ir ao encontro de significados culturalmente difundidos que associam a transexualização a um transtorno mental. O pai de Gisele a levou, inicialmente, a um psiquiatra. A mãe de Arthur entende que ele estava com problemas mentais. Entretanto, a forma como as famílias lidaram foi diferente: os pais de Gisele aceitaram sua transexualidade, já os familiares de Arthur toleravam que o mesmo fosse homossexual, mas não transexual.

A relação com a família indicou aspectos de permanência na análise intrageracional dos representantes do meio e mais velhos: preconceito ou distanciamento.

\section{Conclusões}


Considera-se que no processo de transexualização na infância, descritos pelos (as) transexuais participantes, não há uma autoidentificação abrupta de suas transexualidades. Ocorre sim, uma mudança complexa, ao longo de suas histórias, em que estão configurados os significados compartilhados e resistentes às mudanças, os quais permanecem e sustentam a ideia de cada gênero - masculino e feminino - tem funções diferenciadas devido aos seus corpos. Os significados mantêm-se fossilizados na cultura, transmitidos intergeracionalmente. Convivem, por outro lado, nesse mesmo processo, como a outra face da mesma moeda, as experiências cotidianas que permitem uma modificação e, quiçá, uma ruptura por meio de novos sentidos. Os sentidos, portanto, não são elementos fixos, mas sim, produzidos através da linguagem e da sua função comunicativa estabelecidas pelas interações sociais, simbólicas e históricas. Por ser algo experiencial e repleto de cargas afetivas, o sentido é pessoal e mutante.

As categorias de sentido temáticas permitiram a visão de um mundo permissível ou não da criança e das brincadeiras: aqueles que tiveram contexto menos livre, como os três transexuais masculinos e as duas transexuais da geração do meio e mais velha, precisaram adotar estratégias de disfarce para não sofrerem preconceito por parte dos pais e das outras crianças. O sentir-se diferente das outras crianças, o desejo de participar de brincadeiras, usar roupas e cortes de cabelos contrários ao seu "papel social de gênero" manteve-se em todos os relatos.

A aparência é um elemento bastante pontual no processo de transexualização dos seis sujeitos da pesquisa. Ter que parecer menino ou menina, estar conforme os padrões de gênero heteronormativos levam os/as seis transexuais entrevistados a usarem estratégias de disfarce para adaptarem 0 visual. A autoimagem torna-se importante para que o outro o aceite. $O$ olhar do meio interfere nas visões de que Gisele, Bridget, Joana, Arthur, Zé e Sansão possuem sobre seus corpos. A aparência e o parecer ser fazem parte de uma negociação social com a família e comunidade. $O$ ideal de corpo está pautado em normas sociais do que é uma estrutura corpórea de um menino e de uma menina e seus respectivos comportamentos, mantendo-se 0 binarismo. Acompanhando a problemática da transexualidade não binária, percebe-se que essa ideia de manutenção dos binarismos macho e fêmea contraria o fenômeno contemporâneo dos transexuais não binários que se consideram pertencentes aos dois universos e não atendem às "regras" para cada gênero.

Por outro lado, entende-se que esse "reforço" aos estereótipos de gênero não é culpa da pessoa transexual. Transexuais são obrigados (as) socialmente a se enquadrarem em regras binárias de gênero 
para não terem suas identidades deslegitimadas. Durante o processo transexualizador para a cirurgia de transgenitalização, os profissionais da saúde solicitam essa "adequação" visual e comportamental, como uma espécie de modelo como requisito para a intervenção cirúrgica, além da própria sociedade, na figura da família e colegas, afirmar que só existem dois gêneros com seus papéis já definidos, sem "ambiguidades" (Aran, 2006, Silva, 2013).

A família também marcou as histórias de vida dos personagens privilegiados dessa pesquisa. Estratégias de adaptação nas brincadeiras com os amigos, refúgio em histórias em quadrinhos ou em filmes para evitar constrangimentos. Apenas Gisele, a representante feminina mais nova, relembra que não sofreu represálias dos pais, parentes e colegas, o que facilitou a expressão de sua transexualidade. Tal fato se configura como indício de ruptura presente na produção de sentido acerca da família.

Os resultados da análise das experiências narradas permitiram compreender que a transexualização não é um fenômeno que, obrigatoriamente, ocorre na adolescência ou na fase adulta, mas uma produção em constante movimento, evidenciando seu caráter flexível e de práxis, em conformidade com as mudanças sociohistóricas.

As análises possibilitaram, ainda, compreender a relação entre identidade e processo de transexualização. A transformação corporal é uma maneira de expressão da identidade que atende a si mesmo/a, bem como ao olhar do outro. À medida que os valores da convivência com a diversidade são compartilhados socialmente, e veiculados nos meios de comunicação, embora ainda de forma estereotipada e caricata, impulsionam mudanças e expressões de identidades, e viceversa.

O recorte de análise intergeracional, nas histórias de vida, permitiu observar a manutenção de aspectos do conceito de transexualidade em diferentes períodos e contextos históricos relembrados pelos sujeitos privilegiados. Proporcionou, ainda, visualizar as permanências de significados compartilhados e fossilizados (os comportamentos e regras para homens e mulheres) e as possíveis rupturas (aceitação familiar da geração feminina mais nova e as diferentes estratégias de disfarce). A intrageracionalidade permitiu perceber as nuances e experiências de gênero entre os representantes da mesma geração. As experiências com preconceito familiar, o autoestranhamento em relação ao seu processo de transexualização e as estratégias de disfarce foram presentes entre as mesmas gerações, com exceção das gerações mais novas: a feminina apresentava maior permissividade e não se considerava estranha, mas sempre pertencente ao gênero feminino.

As reflexões teóricas, epistemológicas e metodológicas dos resultados encaminharam a uma concepção processual desses sujeitos. 0 processo de produção da subjetividade é produzido a partir da 
interação com os seus ambientes sociais e contato com as suas histórias, interiorizando informações da cultura, codificando com o que já possuem e conferindo sentido e significado. A História de Vida trata-se de aporte metodológico de suma importância por permitir uma análise de microestruturas sem desconsiderar as significações no nível da história e cultura. Em relação, ainda, ao método, foi observado que os representantes masculinos da geração do meio e os dois representantes da geração mais velha apresentaram maior detalhamento dos datas e fatos históricos e sociais ao narrar suas histórias de vida. Zé lembrava-se da diretora dizendo que ele era estranho no início da Ditadura, em sua infância; Bridget, fugindo da zombaria dos meninos no auge das divas da Era de Ouro de Hollywood; Sansão, isolando-se dos familiares ao ler gibis em estilo formatinho dos anos 60.

O contato do indivíduo com a sua história permite a experiência de conflitos, emoções, contrassensos que vão se estruturando e se modificando. Nesse sentido, considera-se que não existe apenas um modelo de história ou de processo de transexualização para todos, mas vários, o que torna o ser humano fragmentado, experiencial e processual. Assim, os processos de produção dos sujeitos são advindos de seu movimento histórico. As gerações mais novas apresentaram uma permissividade e ousadia maior em relação às suas transexualizações: a transexual feminina sempre se considerou uma menina e se comportava como uma; o representante masculino, inicialmente, sentiu um autoestranhamento, mas logo enfrentou seus pais, para poder cortar os cabelos. As gerações do meio e mais velhas encontraram ambientes mais hostis, necessitando de estratégias de disfarce e pouca ousadia para enfrentar seus familiares e colegas. Entretanto, as táticas de disfarce se diferenciavam, a depender do meio em que faziam parte e das suas histórias.

Espera-se que o presente artigo possa contribuir na área da Psicologia Social e nos estudos relacionados ao processo de transexualização na infância e gênero. Por fim, considerou-se que as reflexões aqui apresentadas permitiram o surgimento de outras questões: a transexualidade nos meios midiáticos e artísticos voltados para o público infantil. A utilização de personagens transexuais no cinema, quadrinhos, desenhos animados possibilitaria uma relação com a diversidade sexual e atingiria os significados perpetuados por meio dos preconceitos? Qual a relevância política da criação de personagens transexuais e travestis em quadrinhos e desenhos infantis? Esses são questionamentos a serem investigados em futuras pesquisas.

\section{Referências}


Anacleto, A. A. A., \& Maia, A. C. B. (2009). Gênero na infância: análise do filme "La vie in rose" como instrumento pedagógico em educação sexual. Revista Ibero-Americana de Estudos em Educação, 4(3), 01-11.

Aran, M. A (2006). Transexualidade e a gramática normativa do sistema sexo - gênero. Ágora, 9(1), 49-63.

Aran, M., \& Murta, D. (2009). Do diagnóstico de transtorno de identidade de gênero às redescrições da experiência da transexualidade: uma reflexão sobre gênero, tecnologia e saúde. Physis. 19(1), 15-41.

Araújo, L. R. de. (2010). Transexualidade: dos transtornos às experiências singulares. Dissertação de Mestrado não publicada, Universidade Católica de Pernambuco, Pernambuco, PE, Brasil.

Argentieri, S. (2009). Travestismo, transexualismo, transgêneros: identificação e imitação. Jornal Psicanalítico, 77(42), 167-185.

Barbosa, B. C. (2010). Nomes e diferenças: uma etnografia dos usos das categorias travesti e transexual. Dissertação de Mestrado não publicada, Universidade de São Paulo, São Paulo, SP, Brasil.

Bardin, L. (2009). Análise de Conteúdo. São Paulo: Edições 70.

Bento, B. (2006). A Reinvenção do Corpo: Sexualidade e Gênero na Experiência Transexual. Rio de Janeiro: Garamond.

Bento, B. (2009) A diferença que faz a diferença: corpo e subjetividade na transexualidade. Revista Bagoas, 04, 95-112.

Brandão, L., Smith, V., Sperb, T. M., \& Parente, M. A. de M. P. (2006) Narrativas intergeracionais. Psicologia Reflexão e Crítica, 19(1), 98-105.

Bruns, M. A. de T., \& Pinto, M. J. C. (2003) Vivência Transexual: O corpo desvela seu drama. Campinas: Átomo.

Butler, J. (2010) Problemas de Gênero: Feminismo e Subversão da identidade. Rio de Janeiro: Civilização Brasileira.

Caregnato, R. C. A., \& Mutti, R. (2006). Pesquisa Qualitativa: Análise do discurso versus análise de conteúdo. Texto Contexto Enfermagem, 15(4), 679-84.

Carvalho, M. F. de L. (2011). Que mulher é essa? Identidade, política e saúde no movimento de travestis e transexuais. Dissertação de Mestrado não publicada, Universidade do Estado do Rio de Janeiro, Rio de Janeiro, RJ, Brasil.

Ceccarelli, P. R. (2008). Transexualismo. São Paulo: Casa do Psicólogo.

Chizzotti, A. (2000). Pesquisa em ciências humanas e sociais. São Paulo: Cortez.

Ciampa, A. (2005). A estória de Severino e a História da Severina. São Paulo: Brasiliense.

Delgado, L. de A. N. (2010). História Oral: Memória, tempo e identidades. Belo Horizonte: Autêntica. 
Espinosa, B. de. (1971). Tratado sobre a reforma do entendimento. Lisboa: Livros Horizonte.

Flick, U. (2009). Introdução à pesquisa qualitativa. Porto Alegre: Artmed.

Gagnon, J. (2006). A interpretação do desejo. Ensaios sobre o estudo da sexualidade. Rio de Janeiro: Garamond.

Graziottin, A. , \& Verde, J. B. (1997) Transexualismo: O enigma de identidade. São Paulo: Editora Paulus.

Hennigen, I. (2006). Subjetivação como produção cultural: fazendo uma outra psicologia. Psicologia e Sociedade, 18(2), 47-53.

Humerez, D. C.(1998). História de Vida: Instrumento para captação de dados na pesquisa qualitativa. Revista Acta Enfermagem, 1, 32-37.

Laqueur, T. (2001). Representando o Sexo. In T. Laqueur (Org.). Inventando o Sexo: Corpo e Gênero dos Gregos a Freud (pp.151-188). Rio de Janeiro: Relume Dumará.

Lima, W. M. (2011). Breve história do devir-corpo. In: H. de A. L. Leitão (Org.) Coisas do gênero: diversidade e desigualdade (pp.45-54). Maceió: Edufal.

Lisboa, A. V., Feres - Carneiro, T., \& Jablonski, B. (2007) Transmissão intergeracional da cultura: um estudo sobre uma família mineira. Psicologia em Estudo, Maringá, 12(1), 51-59.

Louro, G. L. (2000) Pedagogias da sexualidade. In: Louro, G. L. (Org.). O corpo educado: Pedagogias da sexualidade (pp. 0734). Belo Horizonte: Autêntica.

Minayo, M. C. de S. (2002). O desafio do conhecimento: pesquisa qualitativa em saúde. São Paulo / Rio de Janeiro: HUCITEC ABRASCO.

Molon, S. I. (2003). Subjetividade e Constituição do Sujeito em Vygotsky. Petrópolis: Vozes.

Nicholson, L. (2000). Interpretando o gênero. Revista Estudos Feministas, Florianópolis, CFH/CCE/UFSC, 18(2), 09-41.

Oliveira, A. A. S., Levi, L. R. M., \& Rodrigues, N. M. (2010). Jovens relembrando contos e lendas à beira-mar: memória psicossocial e intergeracionalidade. In: T. C. G., Guimarães, \& S. M. G., Sousa (Orgs.). Jovens, espaços de sociabilidade e processos de formação (pp. 37- 52). Brasília: Secretaria Especial dos Direitos Humanos; Goiânia: Editora PUC-Goiás: Cânone Editorial.

Ozório, L. (2007). Perspectivas da pesquisa comunitária: comunidade como práxis e seus diálogos com as histórias orais de vida. Estudos e pesquisas em psicologia, $7(1), 31-44$.

Pino, A. (2005). A criança, um ser cultural ou da passagem do biológico ao simbólico. In: A. Pino (Org.). As Marcas do Humano: às origens da constituição cultural da criança na perspectiva de Lev S. Vigotski. (pp. 43-59). São Paulo: Cortez. 
Silva, A. L., \& Oliveira, A. A. S. (2013). Transexualidade/travestilidade na literatura brasileira: sentidos e significados. Arquivos Brasileiros de Psicologia, 65(2), 274287.

Silva, A. L. (2013) Processo de transexualização: uma análise inter e intrageracional de histórias de vida. Dissertação de Mestrado não publicada, Universidade Federal de Alagoas, Maceió, AL, Brasil.

Stadler, H., \& Carmo, L. T. F. do. (2011) Identidade de gênero como ferramenta política entre as lideranças femininas da pesca em Pernambuco. In $\mathrm{H}$. de A. L. Leitão (Org.). Coisas do gênero: diversidade e desigualdade (pp.179-190). Maceió: Edufal.

Teixeira, F. do B. (2009). Vidas que desafiam corpos e sonhos: uma etnografia do construir-se outro no gênero e na sexualidade. Tese de Doutorado não publicada, Universidade Estadual de Campinas, Campinas, SP, Brasil.

Turato, E. R. (2008). Métodos quantitativos e qualitativos na área de saúde: definições, diferenças e seus objetos de pesquisa. Revista Saúde Pública, 39(3), 507-514.

Vigotski, L. S. (2007). A formação social da mente: o desenvolvimento dos processos psicológicos superiores. São Paulo: Martins Fontes. (Originalmente publicado em 1984)

Vigotski, L. S. (2008). Pensamento e Linguagem. São Paulo: Martins Fontes. (Originalmente publicado em 1987)

Vigotski, L. S. (2010) Teoria e Método em Psicologia. São Paulo: Martins Fontes (Originalmente publicado em 1982).

Zambrano, E. (2003). Trocando os documentos - Um estudo antropológico sobre a cirurgia de troca de sexo. Dissertação de Mestrado não publicada, Universidade do Rio Grande do Sul, Rio Grande do Sul, RS, Brasil.

Zanella, A. V., Dassoler, T. R., Reis, A. C., Titon, A. P., \& Urnau, L. C. (2007). Questões de método em textos de Vigotski: contribuições à pesquisa em Psicologia. Psicologia e Sociedade; 19(2), 25-33.

\section{Endereço para correspondência \\ Alexsander Lima da Silva}

Universidade Federal de Alagoas (UFAL)

Instituto de Psicologia. Pós-Graduação em Psicologia. Sala da coordenação do curso de Psicologia

Av. Lourival Melo Mota, s/n, Tabuleiro dos Martins, CEP 57072-900, Maceió - AL, Brasil

Endereço eletrônico: alexsanderlima1983@bol.com.br

Adélia Augusta Souto de Oliveira

Universidade Federal de Alagoas (UFAL)

Instituto de Psicologia. Pós-Graduação em Psicologia. Sala da coordenação do curso de Psicologia 
Av. Lourival Melo Mota, s/n, Tabuleiro dos Martins, CEP 57072-900, Maceió - AL, Brasil

Endereço eletrônico: adeliasouto@ip.ufal.br

Recebido em: $17 / 09 / 2014$

Reformulado em: 10/03/2015

Aceito para publicação em: 17/03/2015

\section{Notas}

* Mestre em Psicologia pela Universidade Federal de Alagoas. Especialista em Psicologia Clínica e Saúde Mental pelo Centro de Estudos Superiores de Maceió. Graduado em Psicologia pela Universidade Federal de Alagoas.

** Professora Associada da Universidade Federal de Alagoas. Diretora do Instituto de Psicologia. Docente permanente do Programa de Pós-Graduação Stricto Sensu em Psicologia na mesma universidade. Doutora em Psicologia Social pela Pontifícia Universidade Católica de São Paulo e Pós-doutorada em Psicologia Social pela Universidad de Barcelona. Integrante do GT da ANPEPP: A Psicologia Sócio-histórica no contexto de desigualdade social brasileiro. 